\title{
SPECIAL NANOFIBER SCAFFOLD DESIGNED FOR CELLULAR PRODUCTS IN THE TREATMENT OF CHRONIC WOUNDS
}

\author{
${ }^{1}$ Petr BRAŤKA, ${ }^{2}$ Matej BUZGO, ${ }^{3}$ Hana WALASKÁ, ${ }^{4}$ Josef ROSINA, ${ }^{1}$ Martin ČERVEŇÁK, \\ ${ }^{1}$ Matěj LOUDA \\ ${ }^{1}$ Grade Medical s.r.o., Řevnice, Czech Republic, EU \\ 2InoCure s.r.o., Čelákovice, Czech Republic, EU \\ ${ }^{3}$ ING MEDICAL s.r.o., Prague, Czech Republic, EU \\ ${ }^{4}$ Faculty of Biomedical Engineering, Czech Technical University in Prague, Kladno, Czech Republic, EU
}

https://doi.org/10.37904/nanocon.2020.3753

\begin{abstract}
In this work we have prepared and characterized several types of nanofibers to create unique nanofiber substrates as a medical device for long-term non-healing wound treating using cellular products. Our nanofibers are based on biodegradable polymers such as polycaprolactone (PCL), poly(lactide-cocaprolactone) (PLCL), poly(vinyl)alcohol (PVA), polyethyleneimine (PEI) and hyaluronic acid. Prepared nanofiber carriers were specifically adjusted for the autologous MSCs (mesenchymal stromal cells) applications on the chronic wound. In addition, the nanofiber sheets were constructed as a biodegradable material to guarantee proper timing of its resorption in a chronic wound during the healing process. Furthermore, the effect of growth factors on MSC proliferation was tested. The release of bFGF from adsorbed lipid particles was tested. The results show increased proliferation of MSCs. Despite fast increasing advanced technologies in healthcare, chronic wound treating tends to be still very difficult and challenging. Our developed nanofiber-based dressings are very promising for poorly healing wound therapy using MSCs. The main goal is to make chronic wound healing more effective and decrease a time of healing process.
\end{abstract}

\section{INTRODUCTION}

In the recent years, there has been a growing interest in nanofiber materials for biomedical use including wound healing [1]. Nanofibers due to their properties (huge surface area, persistent diameter, high aspect ratio, and tailorability) provide multiple advantages for wound healing applications. Nanofibrous structures are most often prepared by electrospinning process [2,3]. During this process polymer nanofibers are prepared by electrospinning from a polymeric solution and trapped on base material (e.g. nonwoven textile). The resulting nanofibrous membranes show high porosity, uniform pore distribution, high pore interconnection and the overall structure mimics extracellular matrix [4]. Electrospinning was shown to enable processing wide range of polymers including synthetic biodegradable (i.e. polylactic acids, polyglycolic acid, polycaprolactone, polyvinyl alcohol, polyethylene oxide), natural biodegradable polymers (i.e. gelatine, collagen, hyaluronic acid, alginate, chitosan) and also synthetic polymers (i.e. polyamide, polyacrylonitrile, polyvinyl difluoride) [5].

As a part of this research several mentioned polymers were used for the preparation of the nanofiber scaffolds. Polycaprolactone $(\mathrm{PCL})$ is biodegradable polyester widely used on biomedical industry. The nanofibers prepared from polycaprolactone show biodegradation depending on molecular weight [6]. PCL nanofibers were shown to support adhesion and proliferation of keratinocytes, melanocytes, and fibroblasts [7]. Recently, we have reported nanofibers from PCL in form of wound dressing [8]. The system showed optimal healing by utilization as integrative wound dressing with low exchange rates. Adhesive properties of fibers upon exchange showed slower regeneration by removing of newly formed tissue upon removal. The PCL nanofibers were also 
shown to stimulate the healing upon functionalization with blood derivatives $[9,10]$. Polycaprolacton-co-lactic acids (PLCL) are biodegradable polyester which shows higher elasticity then PCL [11], but this material is much less explored for electrospinning compered to PCL. Nevertheless, PLCL was shown to produce scaffolds in combination with natural polymers (i.e. collagen and heparin) [12]. Another fiber-forming polymer is poly(vinyl)alcohol (PVA), which is a biodegradable polymer with hydrophilic properties. PVA was shown to produce nanofiber scaffolds for wound dressings with potential for non-adhesive dressings [8]. Polyethyleneimine (PEI), and its derivatives, are polycationic polymers also widely used for electrospinning biocompatible scaffolds fabrication [e.g. 13]. Khanam et al. has developed and standardized the PEI-based scaffold, which promotes the direct formation of new tissue.

Moreover, described biopolymers are utilized for increase of cell adhesion and biocompatibility of natural fibers. The nanofiber-based wound dressings were shown to be further functionalized by blending with hyaluronic acid [14]. Hyaluronic acid, that has unique capacity in retaining water, is neutral skin component involved in its moisturizing process [15]. Hussein et al. [16] has reported nanofiber based wound dressings formed by blend electrospinning of PVA and hyaluronic acid with L-arginine. The system showed increased wound healing potential in vitro.

\section{METHODS}

\subsection{Electrospinning of polycaprolactone (PCL)}

Polycaprolactone (MW 45,000; Sigma Aldrich) was dissolved in chloroform: ethanol (9:1). The concentration of PCL was set $28 \%(\mathrm{w} / \mathrm{v})$ and solution was stirred overnight at $50{ }^{\circ} \mathrm{C}$. The formed solution was electrospun on InoSPIN MINI (InoCure) device using G10 needle electrode at $100 \mathrm{ml} / \mathrm{h}$ dosing rate. The voltage was set at $+45 \mathrm{kV},-35 \mathrm{kV}$ and distance of $200 \mathrm{~mm}$. The resulting nanofibers were collected on rotating drum collector (500 rpm). Each batch of fibers was spun from $30 \mathrm{ml}$ of solution with deposition area of $1100 \mathrm{~cm}^{2}$.

\subsection{Electrospinning of polycaprolacton-co-lactic acids (PLCL)}

PLCL (Corbion) was dissolved in DMF. The concentration of PLCL was set $15 \%(\mathrm{w} / \mathrm{v})$ and solution was stirred overnight at $50^{\circ} \mathrm{C}$. The formed solution was electrospun on InoSPIN MINI (InoCure) device using G20 needle electrode at $30 \mathrm{ml} / \mathrm{h}$ dosing rate. The voltage was set at $+42 \mathrm{kV},-30 \mathrm{kV}$ and distance of $200 \mathrm{~mm}$. The resulting nanofibers were collected on rotating drum collector $(500 \mathrm{rpm})$. Each batch of fibers was spun from $30 \mathrm{ml}$ of solution with deposition area of $1100 \mathrm{~cm}^{2}$.

\subsection{Electrospinning of poly(vinyl)alcohol (PVA)}

$10 \%$ (w/v) PVA (40-88; Merck) was dissolved in distilled water with addition of 40,000 ppm glyoxal and 30,000 ppm $\mathrm{H}_{3} \mathrm{PO}_{4}$. The solution was prepared overnight using stirring and heating $\left(80^{\circ} \mathrm{C}\right)$. The formed solution was electrospun on InoSPIN MINI (InoCure) device using linear slit needleless electrode at $100 \mathrm{ml} / \mathrm{h}$ dosing rate. The voltage was set at $+45 \mathrm{kV},-30 \mathrm{kV}$ and distance of $200 \mathrm{~mm}$. The resulting nanofibers were collected on rotating drum collector $(500 \mathrm{rpm})$. Each batch of fibers was spun from $30 \mathrm{ml}$ of solution with deposition area of $1100 \mathrm{~cm}^{2}$. The formed scaffolds were crosslinked at $90{ }^{\circ} \mathrm{C}$ for $5 \mathrm{~min}$.

\subsection{Electrospinning of polyethyleneimine (PEI)}

PCL-PEI scaffolds were prepared by blend electrospinning. Polycaprolactone (MW 45,000; Sigma Aldrich) was dissolved in chloroform: ethanol (9:1). The concentration of PCL was set $28 \%(\mathrm{w} / \mathrm{v})$ and solution was stirred overnight at $50{ }^{\circ} \mathrm{C}$. PEI (Alpha Aesar) was added to the solution in ratio 9:1 (w/v). The formed solution was electrospun on InoSPIN MINI (InoCure) device using G10 needle electrode at $100 \mathrm{ml} / \mathrm{h}$ dosing rate. The voltage was set at $+45 \mathrm{kV},-35 \mathrm{kV}$ and distance of $200 \mathrm{~mm}$. The resulting nanofibers were collected on rotating 
drum collector (500 rpm). Each batch of fibers was spun from $30 \mathrm{ml}$ of solution with deposition area of 1100 $\mathrm{cm}^{2}$.

\subsection{Electrospinning of PVA-HA}

8\% (w/v) PVA (40-88; Merck) was dissolved in distilled water with addition of 40,000 ppm glyoxal and 30,000 ppm $\mathrm{H}_{3} \mathrm{PO}_{4}$. The solution was prepared overnight using stirring and heating $\left(80^{\circ} \mathrm{C}\right)$. After dissolution $1 \%(\mathrm{w} / \mathrm{v})$ of hyaluronic acid (Hyalgan) was added to the solution and left for additional 5 hours to stir at room temperature. The formed solution was electrospun on InoSPIN MINI (InoCure) device using linear slit needleless electrode at $100 \mathrm{ml} / \mathrm{h}$ dosing rate. The voltage was set at $+45 \mathrm{kV},-30 \mathrm{kV}$ and distance of $200 \mathrm{~mm}$. The resulting nanofibers were collected on rotating drum collector $(500 \mathrm{rpm})$. Each batch of fibers was spun from $30 \mathrm{ml}$ of solution with deposition area of $1100 \mathrm{~cm}^{2}$. The formed scaffolds were crosslinked at $90{ }^{\circ} \mathrm{C}$ for 5 $\min$.

\subsection{Characterization by SEM}

Samples were cut to discs (5 mm diameter) and coated with layer of platinum (sput-coater Quorum). The samples were analysed using Tescan Vega electron microscope.

\section{7. $\quad$ MSC cell culture}

Blood marrow was aspirated from the iliac wing of a minipig into a $5 \mathrm{~mL}$-syringe containing $1 \mathrm{~mL}$ PBS and 25 IU heparin under general anesthesia. The mononuclear cells were isolated using gradient separation with the plasma substitute Gelofusine $\AA$. Briefly, blood marrow was mixed with $1.25 \mathrm{~mL}$ Gelofusine $\AA$. After $30 \mathrm{~min}$, the upper and medium layers containing plasma, mononuclear cells, and erythrocytes were aspirated, and centrifuged at $270 \times \mathrm{g}$ for $15 \mathrm{~min}$. Subsequently, the medium layer with mononuclear cells was aspirated and seeded in tissue culture flasks. Adherent cells were cultured in Minimum Essential Medium (MEM) (with Lglutamine, PAA) containing 10\% fetal bovine serum (Mycoplex, PAA), $100 \mathrm{IU} / \mathrm{mL}$ penicillin, and $100 \mu \mathrm{g} / \mathrm{mL}$ streptomycin. The cells were passaged using the trypsin-EDTA method before confluence was reached. The cells from the third passage were used for the cell culture study.

\subsection{Platelet functionalization}

The PCL-based nanofiber scaffolds, selected as most satisfactory carriers, were tested in combination with thrombocytes to support the MSCs activity and/or viability. Platelets were adsorbed on the surface of the support using the vacuum functionalization device (Grade Medical). The MSCs were seeded in density 40,000 cells $/ \mathrm{cm}^{2}$ on the surface of platelet functionalized PCL nanofibers and PCL nanofibers without platelets. The samples were analysed on day 7 using propidium iodide (Sigma Aldrich) and $\mathrm{DiOC}_{6}$ (Sigma Aldrich) according to Knotek et al [17]. Samples were visualized using confocal microscope (Leica).

\subsection{Doping of nanofiber carriers with growth factors}

The release of basic fibroblast growth factor (bFGF) from lipid particles based on 1-tetradecanol (Sigma Aldrich) drug delivery system was tested subsequently. The solid lipid particles (SLP) based drug delivery system were produced by the functionalization device (Grade Medical) using nano- or micro-emulsification process under the controlled condition (dose, temperature, rotation speed, pressure).

\section{RESULTS AND DISCUSSION}

Electrospinning process showed proper formation of nanofibers using multijet technology. The nanofibers from PCL showed highest production rate with formation up to 10 jets per emitter. In case of PLCL, the electrospinning process was slower and resulted in lower production capacity. PVA and PVA-HA were spun from needleless electrode enabling formation of $>50$ jets. Due to lower production capacity caused by 


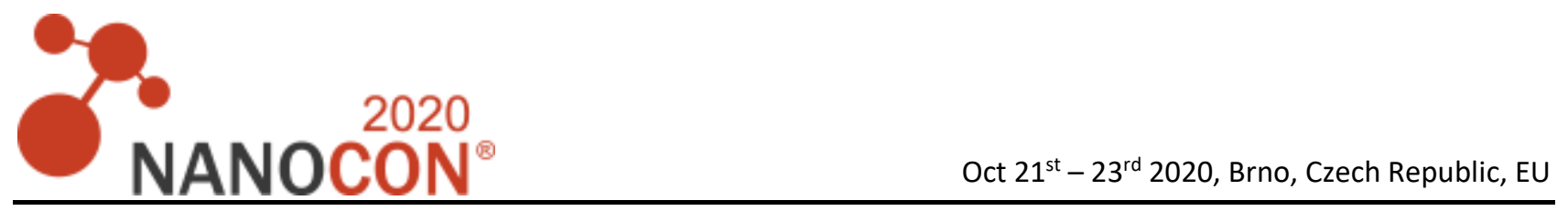

increased surface tension and lower polymer concentration the process was slower and despite increased numbers of jets, the overall productivity was lower than in case of PCL.

The process for all samples resulted in formulation of well solidified scaffolds enabling mechanical handling. The samples from PLCL showed shrinkage of scaffolds due to relaxing of mechanical tension in stretched PCLC polymeric chains. PCL showed highest mechanical stability.

The analysis using electron microscopy showed proper fibrous morphology (Figures 1, A-D). PCL showed morphology with bimodal distribution of nanofibers $(221 \pm 48 \mathrm{~nm}$ - nanofibrous fraction, $536 \pm 52 \mathrm{~nm}$ submicrofiber fraction). The morphology also showed minor population of microfibers. In case of PLCL the morphology of nanofibers was $750 \pm 120 \mathrm{~nm}$ and showed partially beaded structure. In case of PVA the fibers showed size $250 \pm 32 \mathrm{~nm}$ with low fiber deviation and homogenous structure. In case of PVA-HA combination was observed fibers with a diameter $270 \pm 45 \mathrm{~nm}$. PCL-PEl electrospinning resulted in formation of fibers with bimodal distribution of nanofibers ( $240 \pm 65 \mathrm{~nm}$ - nanofibrous fraction, $420 \pm 84 \mathrm{~nm}$ submicrofiber fractions).

The overall structure of the fibers corresponds to macroscopic properties of nanofibrous layer. The low presence of defects improves mechanical properties of fibers.
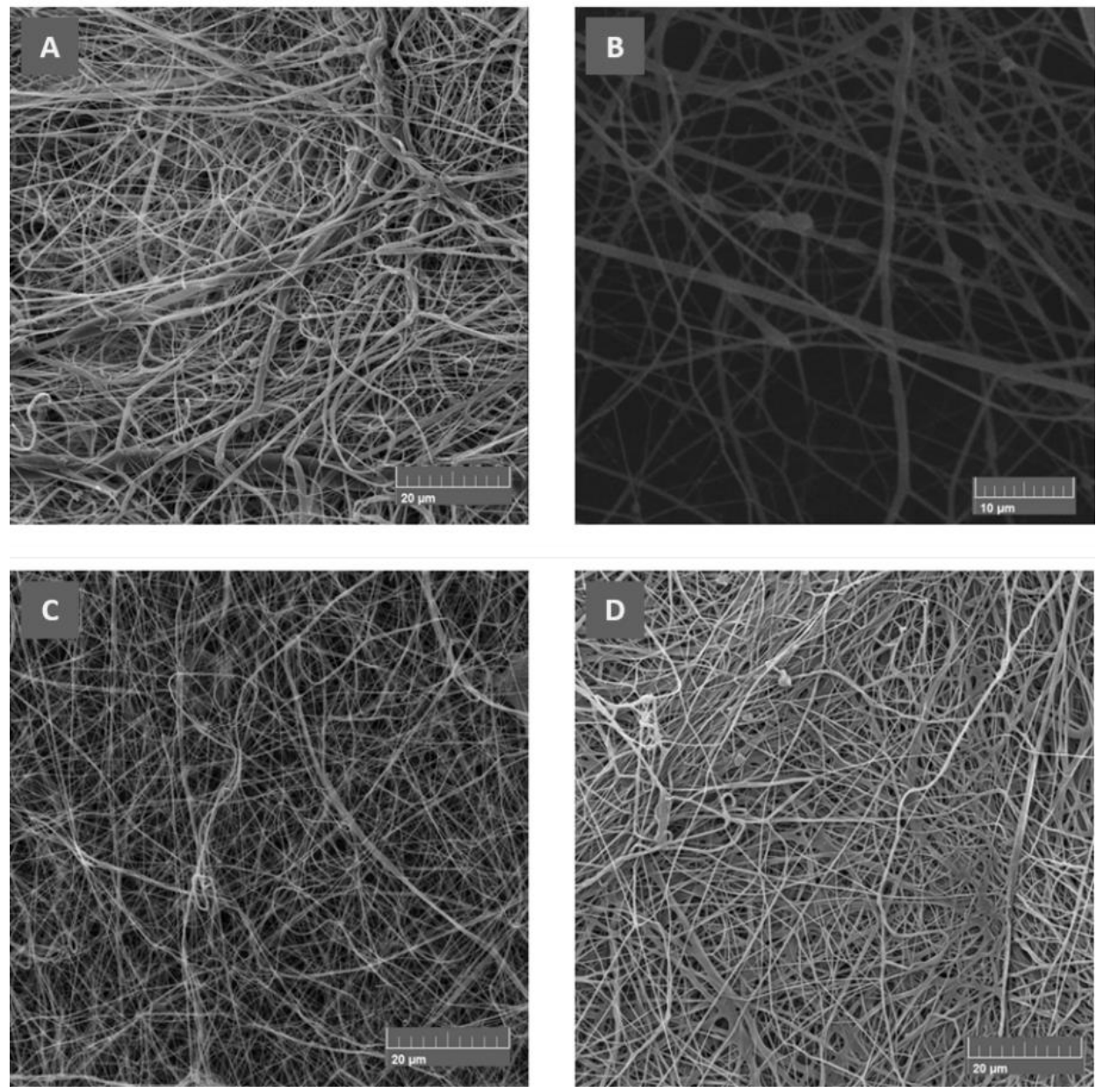

Figure 1 SEM images of electrospun nanofiber scaffolds based on PCL (A), PLCL (B), PVA (C) and PVA-HA (D)

The initial results of in vitro testing of PCL with adhered thrombocytes have shown increased cell proliferation on platelet carriers compared to PCL nanofibers (see Figure 2). The results indicate bioactivity retention of thrombocytes after vacuum deposition. 

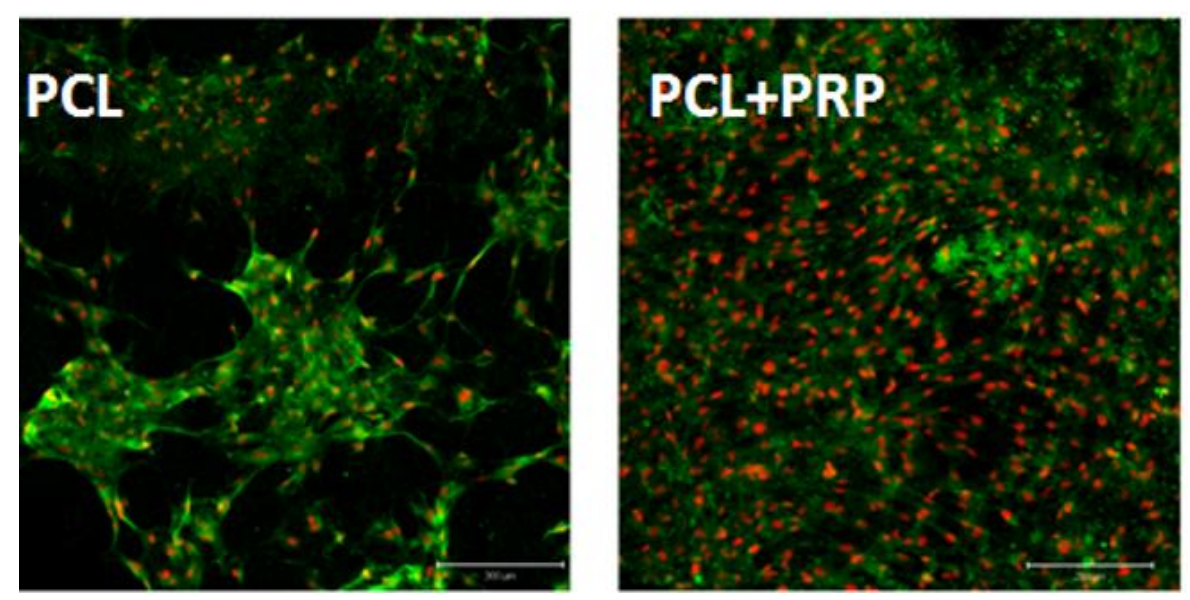

Figure 2 Confocal microscope images of MSC proliferation on non-doped PCL carrier (left) and carrier with platelet-rich plasma (PRP) (right)

Furthermore, we gave showed that vacuum deposition enables adsorption of solid lipid particles on the surface of nanofibers. The scaffold morphology shows microparticles attached on the surface of fibrous structure (Figure 3). The preliminary cell culture study indicates MSC survival on the scaffold with adsorbed SLPS (Figure 4).

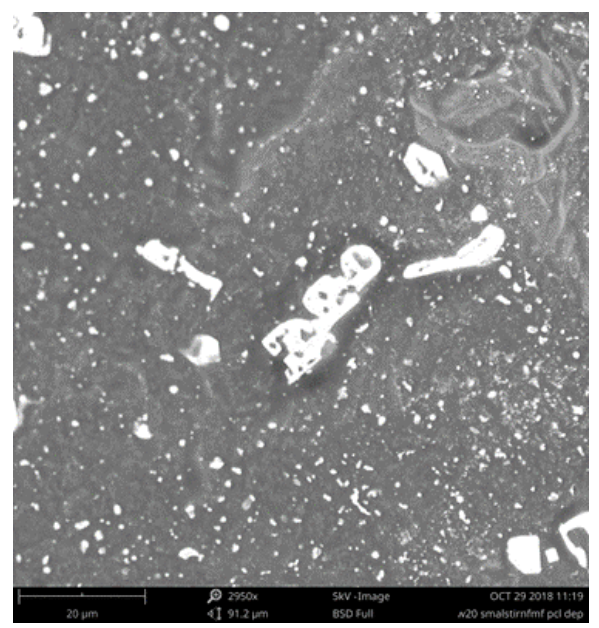

Figure 3 SEM image of SLP adsorbed on PCL nanofibers

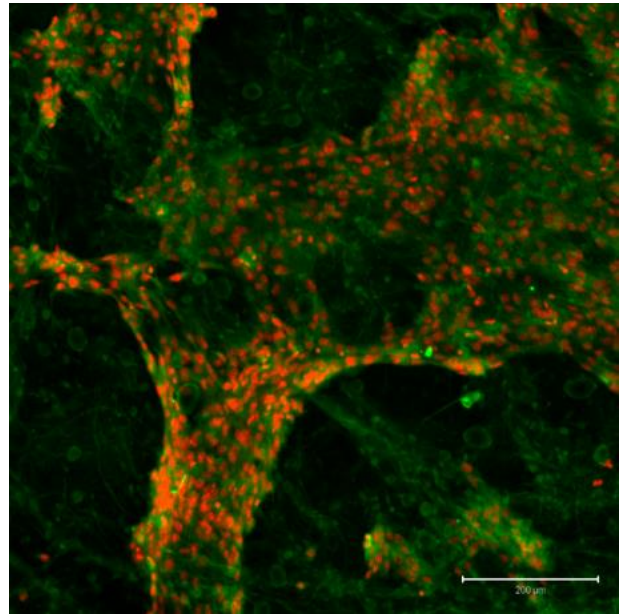

Figure 4 Confocal image of MSC on PCL nanofibers with SLP containing bFGF on day 7 of culture

\section{CONCLUSION}

The electrospinning technology was showed to enable processing of PCL, PLCL, PVA, PEI and PVA-HA for wound dressing applications. The fibers showed beadles structure with different properties of nanofibers which were subsequently tested using MSCs. The samples with both platelets and SLPs showed cell adhesion properties and enabled cellular growth after 7 days in culture. The results suggest that vacuum deposition is a suitable method for functionalization of nanofiber scaffolds. However the potential of the formed scaffolds will be further evaluated in long-term cell culture and in vivo conditions, results obtained indicate these nanofibrous scaffolds as suitable carrier for MSCs themselves as well as carriers of drug delivery system for controlled release of supportive substances, such as soluble pro-regenerative factors, used during the MSCs therapy. Such a nanofiber-based dressings are then very promising for poorly healing wound therapy using MSCs with the main goal to make chronic wound healing more effective and decrease a time of healing process. 


\section{ACKNOWLEDGEMENTS}

This work was performed as part of the project FV20422 "Development of nanofibrous scaffolds ensuring application of cellular products, including physical stimulation effect, with the intended purpose of the treatment of chronic wounds".

\section{REFERENCES}

[1] STOCCO, T.D., BASSOUS, N.J., ZHAO, S., GRANATO, A.E.C., WEBSTER, T.J., LOBO, A.O. Nanofibrous scaffolds for biomedical applications. Nanoscale. [online]. 2018, vol. 10, pp. 12228-12255. Available from: https://doi.org/10.1039/c8nr02002g.

[2] TAHALYANI, J., RAHANGDALE, K.K., AEPURU, R., KANDASUBRAMANIAN, B., DATAR, S. Dielectric investigation of a conducting fibrous nonwoven porous mat fabricated by a one-step facile electrospinning process. RSC Adv. [online]. 2016, vol. 6, pp. 36588-36598. Available from: https://doi.org/10.1039/c5ra23012h.

[3] ARUCHAMY, K., MAHTO, A., NATARAJ, S.K. Electrospun nanofibers, nanocomposites and characterization of art: insight on establishing fibers as product. Nano-Struct Nano-Objects. [online]. 2018, vol. 16, pp. 45-58. Available from: https://doi.org/10.1016/j.nanoso.2018.03.013.

[4] SILL, T.J., VON RECUM, H.A. Electrospinning: applications in drug delivery and tissue engineering. Biomaterials. [online]. 2008, vol. 29, no. 13, pp. 1989-2006. Available from: https://doi.org/10.1016/.j.biomaterials.2008.01.011.

[5] MEIRELES, A.B., CORREA, D.K., SILVEIRA, J.V.W., MILLÁS, A.L.G., BITTENCOURT, E., DE BRITO-MĚLO, G.E.A., GONZÁLEZ-TORRES, L.A. Trends in polymeric electrospun fibers and their use as oral biomaterials. Experimental biology and medicine (Maywood, N.J.). [online]. 2018, vol. 243, no. 8, pp. 665-676. Available from: https://doi.org/10.1177/1535370218770404.

[6] GOLDBERG, D. A review of the biodegradability and utility of poly(caprolactone). Journal of environmental polymer degradation. [online]. 1995, vol. 3, pp. 61-67. Available from: https://doi.org/10.1007/BF02067481.

[7] VOCETKOVA, K., BUZGO, M., SOVKOVA, V., BEZDEKOVA, D., KNEPPO, P., AMLER, E. Nanofibrous polycaprolactone scaffolds with adhered platelets stimulate proliferation of skin cells. Cell proliferation. [online]. 2016, vol. 49, no. 5, pp. 568-578. Available from: https://doi.org/10.1111/cpr.12276.

[8] BUZGO, M., PlenCNER, M., RAMPICHOVA, M., LITVINEC, A., PROSECKA, E., STAFFA, A., KRALOVIC, M., FILOVA, E., DOUPNIK, M., LUKASOVA, V., VOCETKOVA, K., ANDEROVA, J., KUBIKOVA, T., ZAJICEK, R., LOPOT, F., JELEN, K., TONAR, Z., AMLER, E., DIVIN, R., FIORI, F. Poly-ع-caprolactone and polyvinyl alcohol electrospun wound dressings: adhesion properties and wound management of skin defects in rabbits. Regen Med. [online]. 2019 May, vol. 14, no. 5, pp. 423-445. Available from: https://doi.org/10.2217/rme-2018-0072.

[9] SOVKOVA, V., VOCETKOVA, K., RAMPICHOVA, M., MICKOVA, A., BUZGO, M., LUKASOVA, V., DANKOVA, J., FILOVA, E., NECAS, A., AMLER, E. Platelet lysate as a serum replacement for skin cell culture on biomimetic PCL nanofibers. Platelets. [online]. 2018, vol. 29, no. 4, pp. 395-405. Available from: https://doi.org/10.1080/09537104.2017.1316838.

[10] LUKÁŠOVÁ, V., BUZGO, M., VOCETKOVÁ, K., SOVKOVÁ, V., DOUPNÍK, M., HIMAWAN, E., STAFFA, A., SEDLÁČEK, R., CHLUP, H., RUSTICHELLI, F., AMLER, E., RAMPICHOVÁ, M. Needleless electrospun and centrifugal spun poly- $\varepsilon$-caprolactone scaffolds as a carrier for platelets in tissue engineering applications: $A$ comparative study with hMSCs. Mater Sci Eng C Mater Biol Appl. [online]. 2019, vol. 97, pp. 567-575. Available from: https://doi.org/10.1016/j.msec.2018.12.069.

[11] JEONG, S.I., KIM, S.H., KIM, Y.H., JUNG, Y., KWON, J.H., KIM, B-S., LEE, Y.M. Manufacture of elastic biodegradable PLCL scaffolds for mechano-active vascular tissue engineering. Journal of biomaterials science. Polymer edition. [online]. 2004, vol. 15, pp. 645-660. Available from: https://doi.org/10.1163/156856204323046906.

[12] KWON, I.K., MATSUDA, T. Co-Electrospun Nanofiber Fabrics of Poly(I-lactide-co-e-caprolactone) with Type I Collagen or Heparin. Biomacromolecules. [online]. 2005, vol. 6, no. 4, pp. 2096-2105. Available from: https://doi.org/10.1021/bm050086u.

[13] KHANAM, N., MIKORYAK, C., DRAPER, R.K., BALKUS, K.J. Electrospun linear polyethyleneimine scaffolds for cell growth. Acta Biomaterialia. [online]. 2007, vol. 3, no. 6, pp. 1050-1059. Available from: https://doi.org/10.1016/j.actbio.2007.06.005. 
[14] SNETKOV, P., MOROZKINA, S., USPENSKAYA, M., OLEKHNOVICH, R. Hyaluronan-Based Nanofibers: Fabrication, Characterization and Application. Polymers. [online]. 2019, vol. 11, p. 2036 (1-25). Available from: https://doi.org/10.3390/polym11122036.

[15] PAPAKONSTANTINOU, E., ROTH, M., KARAKIULAKIS, G. Hyaluronic acid: A key molecule in skin aging. Dermato-endocrinology. [online]. 2012, vol. 4, no. 3, pp. 253-258. Available from: https://doi.org/10.4161/derm.21923.

[16] HUSSEIN, Y., E EL-FAKHARANY. M., KAMOUN, E. A., LOUTFY, S. A., AMIN, R., TAHA, T. H., SALIM, S.A., AMER, M. Electrospun PVA/hyaluronic acid/L-arginine nanofibers for wound healing applications: Nanofibers optimization and in vitro bioevaluation. International Journal of Biological Macromolecules. [online]. 2020, Available from: https://doi.org/10.1016/.ijibiomac.2020.07.126.

[17] KNOTEK, P., POUZAR, M., BUZGO, M., KRIZKOVA, B., VLCEK, M., MICKOVA, A., PLENCNER, M., NAVESNIK, J., AMLER, E., BELINA, P. Cryogenic grinding of electrospun poly- $\varepsilon$-caprolactone mesh submerged in liquid media. Materials Science \& engineering. C, Materials for Biological Applications. [online]. 2012, vol. 32, no. 6, pp. 1366-1374. Available from: https://doi.org/10.1016/j.msec.2012.04.012. 